\title{
La percepción de los problemas del overtourism en Barcelona
}

\author{
The Perception of Overtourism Issues in Barcelona
}

\author{
ANTONIO ÁLVAREZ-SOUSA (Universidade da Coruña)
}

Artículo recibido: 6 de mayo de 2020

Solicitud de revisión: 7 de julio de 2020

Artículo aceptado: 8 de octubre de 2020

\begin{abstract}
Álvarez-Sousa, Antonio (2020). La percepción de los problemas del overtourism en Barcelona. Recerca. Revista de Pensament i Análisi, 26(1), pp. 59-92. doi: http://dx.doi.org/10.6035/Recerca.2021.26.1.4
\end{abstract}

Resumen

El objetivo de esta investigación es analizar la percepción de los residentes sobre el overtourism en Barcelona y el perfil de los ciudadanos que creen que el turismo no beneficia a su ciudad. También analizamos los motivos que alegan y lo que se publica en los medios de comunicación. Para ello nos basamos en un diseño de triangulación concurrente con análisis cuantitativo y cualitativo. El $16 \%$ de la población considera que el turismo no beneficia a la ciudad. Los motivos más importantes para declarar que el turismo no es beneficioso para la ciudad son de tipo ético, social y económico: la masificación, el incivismo de los turistas, la gentrificación y la pérdida de esencia de los barrios. Estos aspectos negativos son la razón para manifestarse públicamente contra dicho turismo y reclamar un turismo responsable.

Palabras clave: overtourism, sostenibilidad, incivismo, actitud de los residentes, Barcelona.

Abstract

The aim of this research paper is to analyze residents' perception of overtourism in Barcelona nowadays and study the profile of citizens who believe that tourism does not benefit their home city. It also aims to find out the specific reasons they give for such beliefs and examines what is published in the media in this regard. In order to achieve it, we based the study on a concurrent triangulation design including both quantitative and qualitative analysis. The findings revealed that $16 \%$ of the population currently considers that tourism does not benefit the city at all. The main reasons for declaring that tourism is not beneficial to the city are of an ethical, social and economic nature; i.e. mass tourism, the antisocial behavior of tourists, gentrification and neighborhoods losing their traditional character. Such negative points are the reasons for publicly demonstrating against the problem and instead promoting a more responsible tourism. 
Key words: overtourism, sustainability, incivism, resident attitude, Barcelona.

\section{INTRODUCCÓN: OBJETIVOS, PREGUNTAS DE INVESTIGACIÓN Y CONTEXTUALIZACIÓN}

El turismo es una actividad que afecta al desarrollo de las comunidades receptoras y a la calidad de vida de la población, pues muchas veces se practica en el mismo espacio en el que los ciudadanos realizan las actividades cotidianas de trabajo, ocio y descanso. Por ello resulta evidente que en algún momento los residentes y las instituciones que gobiernan la sociedad tengan actitudes positivas o negativas según su percepción de la repercusión que está teniendo en el desarrollo de su ciudad y en la calidad de vida de sus ciudadanos. Cuando se incrementa mucho el número de turistas y se percibe que la repercusión es negativa, se produce lo que se ha denominado como overtourism. Entonces puede llegar un momento en que los ciudadanos se irriten y adopten estrategias de crítica a dicho modelo de turismo, proponiendo un turismo responsable, es decir, un modelo de turismo alternativo que sea más beneficioso para el desarrollo y que no conlleve deterioro de su calidad de vida. ${ }^{1}$

Ubicamos nuestro estudio en un contexto teórico-académico, mediático y espacial. El contexto teórico-académico para explicar este fenómeno de overtourism, que implica la irritación de los ciudadanos y el reclamo de un modelo de turismo responsable, se remonta fundamentalmente a Doxey y a Butler. Hace pocos años que se comenzó con las publicaciones sobre el overtourism y aparece perfectamente reflejado en las revistas científicas. El contexto mediático que hizo aflorar el problema y darle extensión internacional, si bien comenzó en el año 2014, se extendió a partir del año 2016 en los medios de comunicación con repercusión internacional y eso fue de la mano de la publicación en todos los medios, en blogs, en redes sociales y en discursos políticos.

1 No queremos entrar a analizar otro fenómeno distinto que se denominó turismofobia por los medios de comunicación. Este alude a acciones de violencia — aunque para algunos simbólica - sobre las infraestructuras, servicios turísticos y los propios turistas por parte de representantes de movimientos sociales. Los vecinos lo reconocen e insisten en no confundir términos y acciones. La siguiente cita lo aclara perfectamente: «Tras la concentración en la misma orilla de la playa, representantes de "La Barceloneta diu Prou” han leído un manifiesto donde aseguran no sufrir turismofobia, “ya que eso sería de idiotas”, argumentaba Sebastián, uno de los portavoces. Desde la asociación se ha insistido mucho en no confundir términos y en no mezclar acontecimientos que están coincidiendo en el tiempo. "A mí no me líes con lo que ha pasado con el bus turístico o con los pinchazos en las ruedas de las bicicletas, porque con eso no estamos de acuerdo', sentenciaba, 'sino que lo que no queremos es quedarnos sin descanso, barrio y sin nuestras casas” (Pauné y Paola, 2017). 
En el ámbito espacial, son muchas las ciudades que están experimentando este problema, si bien nosotros, por motivos de extensión, nos vamos a referir a Barcelona para la recogida y el análisis de los datos.

Los objetivos de nuestra investigación se centran en analizar el porcentaje de ciudadanos que están concienciados del overtourism, el perfil de dichos ciudadanos, las razones concretas que manifiestan para no apoyar el turismo masivo y las estrategias que siguen para manifestar su descontento. En relación con dichos objetivos, intentamos responder a las siguientes preguntas: ¿qué porcentaje de ciudadanos manifiesta que el turismo es negativo para su ciudad y su calidad de vida?, ¿qué perfil sociodemográfico tienen dichos ciudadanos?, ¿qué razones manifiestan para declarar que el turismo es negativo?, ¿son similares las razones manifestadas mediante encuesta a los ciudadanos de las que resultan de analizar la información periodística?, ¿qué actores están implicados en el problema?, ¿qué estrategias siguen para manifestar su descontento?, ¿qué acciones proponen para cambiar el sistema por un turismo responsable? y ¿qué teoría consideramos que se puede inducir para comprender este problema?

Después de presentar las teorías existentes para abordar esta problemática, presentamos las posibles hipótesis que se contrastarán en la parte cuantitativa. Seguidamente presentamos la metodología utilizada, que es una combinación de cuantitativa y cualitativa, indicando las técnicas de recogida y análisis de datos y los programas informáticos que utilizamos. Posteriormente, presentamos los resultados de datos de la fase cuantitativa y, después, los de la fase cualitativa. Concluimos dando respuesta a los objetivos y las preguntas de la investigación.

\section{MARCO TEÓRICO}

La percepción que tiene la población local sobre los efectos del turismo en la comunidad es muy importante. Uno de los factores que puede conducir al declive del turismo en un destino es que no cumpla con las expectativas de los ciudadanos, es decir, que en lugar de considerar que es positivo para el desarrollo de la ciudad, sea percibido como un problema y que tengan una actitud negativa hacia el turismo.

Algunos autores sostienen que la percepción que tienen los ciudadanos del efecto del turismo pasa por varias fases: euforia, apatía, molestias y antagonismo (Doxey, 1975). Pero, como indicó Butler (1980), si se realizan acciones 
adecuadas puede venir una nueva fase de aceptación. De ahí el interés de estudiar bien los problemas existentes para proponer soluciones.

En la segunda década del siglo XXI se desencadenó un proceso de overtourism en muchos destinos urbanos del mundo. El overtourism conllevó una serie de movilizaciones por parte de la población que vive en ciudades receptoras de grandes masas de turismo. Este tema cobró gran importancia en la producción académica. En Scopus, el término overtourism aparece en 74 publicaciones desde el año 2018 en que aparece por primera vez hasta marzo del 2020. El más citado de ellos lo fue 74 veces y corresponde al artículo de Koens, Postma y Papp (2018); le siguen el de Muler González, Coromina y Galí (2018), Martín, Guaita y Salinas (2018), Oklevik et al. (2019), Milano, Novelli y Cheer (2019). La idea general que se mantiene - a falta de espacio para analizar cada una de ellas- es que se está produciendo un exceso de turismo de masas sin planificación adecuada, que influye negativamente en la calidad de vida de la población, por lo que se da un conflicto entre los responsables del turismo, los turistas y los empresarios, con la población local que se muestra descontenta con las repercusiones del turismo en la sociedad. Barcelona es una de esas ciudades; los responsables del turismo son conscientes de ello y han establecido una serie de medidas en los últimos años, pero todavía insuficientes (BlancoRomero, Blázquez-Salom y Cánoves, 2018).

Estos conflictos fueron recogidos en la agenda de los medios de comunicación, muchas veces asociados a los movimientos sociales. La prensa acuñó los conflictos de estos movimientos como turismofobia (Huete y Mantecón, 2018), aunque ellos prefieran denominarlos como propios de la capitalismofobia. ${ }^{2}$ Es otro tipo de protesta diferente a las de los vecinos que reclaman acciones contra los problemas que les ocasiona el overtourism. Incluso ya vimos en la cita 1 de este artículo cómo los propios vecinos quieren que no se les confunda con dichos movimientos; son otros actores, otras causas y otras formas de movilización y protesta.

Pero no toda la población que habita en las zonas que experimentan este problema de overtourism percibe que existan problemas, sino que en la misma ciudad hay personas que consideran que el turismo es beneficioso para la ciudad. Distintos autores coinciden en que la conciencia de los conflictos y su manifestación se da fundamentalmente en los estratos intermedios de la sociedad. Los estratos altos tienen medios económicos, poder y prestigio que se

2 Ya indicamos anteriormente que, para nosotros, ese es otro tema diferente alejado del objetivo del análisis de este artículo. 
sobreponen a los conflictos. Los estratos más bajos no tienen el mismo nivel de conciencia, tiempo o poder para enfrentarse a situaciones conflictivas. Sobre los estratos intermedios que toman conciencia y acción ante los conflictos nos dice Lorenzo Cadarso, al explicar las teorías volcánicas del conflicto social, que «la frustración de expectativas puede darse, en cualquier colectivo social, pero [...] se perciben con mayor rotundidad en los estratos intermedios de la sociedad» (Lorenzo Cadarso, 2001: 245).

Las actitudes de la población hacia el turismo y su pensamiento crítico fueron analizadas por distintos autores (Almeida-García, Cortés-Macías, Balbuena-Vázquez e Hidalgo, 2020; Alrwajfah, Almeida-García y Cortés-Macías, 2019; Belisle y Hoy, 1980; Cardona, 2012; Haralambopoulos y Pizam, 1996; Kim, Jun, Walker y Drane, 2015; Lin, Chen y Filieri, 2017; Marin y Halpern, 2011; Meimand et al., 2017; Pizam, 1978; Royo y Ruiz, 2009; Stylidis, Biran, Sit y Szivas, 2014; Um y Crompton, 1987; Wang y Chen, 2015). ${ }^{3}$ Para planificar el turismo es necesario tener en cuenta las percepciones de la población local, debido a que «los residentes pueden desempeñar un papel en la disuasión del sector turístico si la comunidad local muestra un comportamiento hostil hacia los turistas» (Almeida-García, Cortés-Macías, Balbuena-Vázquez e Hidalgo, 2020). Pero no toda la población local opina del mismo modo, sino que existen diferencias en base a distintos factores.

Entre los distintos factores que están influyendo hay un factor contextual que es aceptado entre los estudiosos: el referido a la zona donde habitan las personas. Aquellas que viven en zonas de las ciudades que están más masificadas por el turismo es más probable que se muestren críticas si solo reciben repercusiones negativas del turismo y no reciben beneficios. Como factores individuales, un elemento fundamental es la formación, siendo aceptado que las personas con mayor nivel de formación tienen un mayor pensamiento crítico. Otro factor que se suele considerar importante para la visión crítica del turismo es el apego a la comunidad, el grado de vinculación, considerando menos beneficioso el turismo las personas que tienen mucho apego a los valores y la cultura de la comunidad. También se tiene en cuenta la dependencia económica de las personas con el sector del turismo, siendo de esperar que las personas que dependen del sector consideren con mayor probabilidad que el turismo es beneficioso para la comunidad.

3 Un buen análisis de los distintos autores y sus escritos puede verse en la tabla 1 de Almeida-García, Cortés-Macías, Balbuena-Vázquez e Hidalgo, 2020. 
Estas diferencias pueden verse reflejadas en la figura 1. En dicha figura se parte de las hipótesis de que las actitudes de los ciudadanos ante el turismo y la idea de que el turismo beneficia o perjudica a la comunidad (beneperj) está condicionada por: a) el distrito donde habitan las personas (distrit), siendo más probable que consideren que el turismo perjudica en los barrios más turísticos; $b$ ) las personas que siempre vivieron en la ciudad (siempviv) es más probable que la consideren más importante para vivir ellos y no quieran ver su vida alterada por el turismo; c) el nivel de estudios que tienen, que conforma su espíritu crítico (nestudios), siendo más probable que sean más críticos con el turismo los que tienen más estudios; $d$ ) la lengua que hablan las personas en la vida cotidiana, pues en aquellas comunidades con lengua propia, las personas que suelen hablar esa lengua demuestran mayor apego y, por lo tanto, mayor probabilidad de ser críticos con la repercusiones del turismo (lengcat); a su vez, es probable que entre estudios y lengua exista relación; e) la relación laboral de las personas del sector turístico (relab), siendo más probable que consideren que el turismo beneficia a la ciudad las personas que trabajan en el sector.

\section{Figura 1}

Perspectiva de los beneficios/perjuicios del turismo según las condiciones sociales de existencia de los habitantes

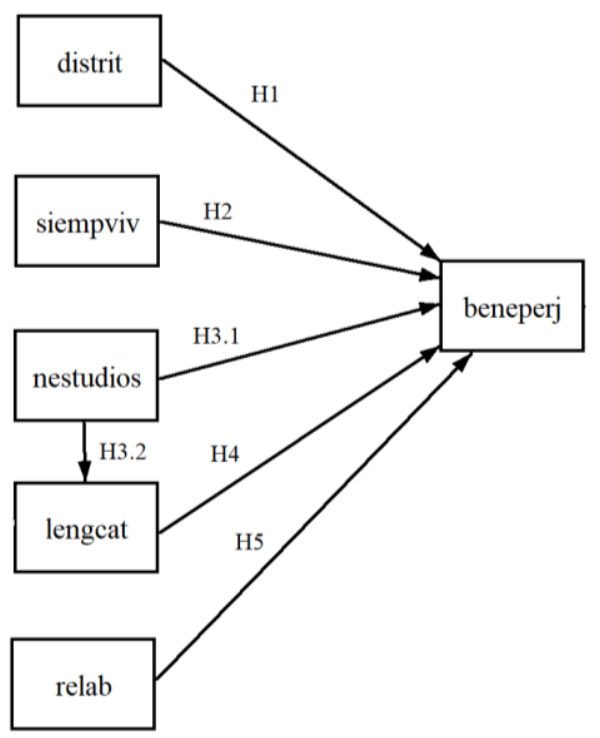

Fuente: elaboración propia 


\section{METODOLOGÍA}

Utilizamos un diseño de triangulación concurrente (Hernández Sampieri, Fernández Collado y Baptista, 2014) con datos y análisis cuantitativo y cualitativo. Nos centramos en datos de la ciudad de Barcelona. Empleamos la metodología cuantitativa para analizar del porcentaje de ciudadanos que considera que el turismo no reporta beneficios a la comunidad. Tomamos los datos de la encuesta «Percepció del turisme a Barcelona» (Ajuntament de Barcelona, 2017), en concreto las preguntas 4 y 6 del apartado «Aspectes de la ciutat». $P_{4}$ : «iEn general cree usted que el turismo es beneficioso para Barcelona? Sí / No / No sabe / No contesta». A los que consideran que el turismo no reporta beneficios, se les hace la pregunta $\mathrm{P} 6$ : «iEn qué aspectos piensa que el turismo no beneficia la ciudad de Barcelona? (Espontáneo, no sugerir. Anotar literalmente con el máximo detalle. Multirespuesta)». El número total de personas consultadas fue de 5014. Para el análisis de los datos, en primer lugar, utilizamos técnicas descriptivas, después técnicas bivariadas y finalmente las ecuaciones estructurales generalizadas (GSEM) con el programa Stata, versión 14. Contrastamos los datos de la encuesta «Percepció del turisme a Barcelona» con los del «Baròmetre de Barcelona» (Ajuntament de Barcelona, 2019), tomando la pregunta sobre los principales problemas de la ciudad y analizando la referencia al turismo.

Además de manifestar en la encuesta el motivo de considerar que el turismo no beneficia a la ciudad, quisimos conocer las acciones llevadas a cabo por los vecinos para manifestar su desacuerdo con el overtourism y reclamo de un turismo responsable. Para ello nos basamos en el análisis cualitativo de artículos que presentaron la noticia de las protestas de los ciudadanos de Barcelona. Tuvimos en cuenta doce artículos. Su selección fue realizada a través de Google, buscando cuatro conceptos conjuntamente: ciudadanos, protesta, turismo y Barcelona. Tomamos los doce primeros artículos que aparecieron en la búsqueda, que son los que figuran al final de la bibliografía, en el apartado titulado «Artículos de prensa analizados». Para su análisis aplicamos la metodología de la Grounded Theory, mediante el programa Atlas.ti.

\section{ANÁLISIS DE LOS DATOS}

En primer lugar, presentamos los resultados del análisis de datos cuantitativo sobre la creencia de que el turismo aporta / no aporta beneficios para la 
ciudad. Analizamos el perfil de las personas que se muestran críticas con el turismo. Seguidamente, analizamos los datos de los motivos por los que consideran que no aportan beneficios. Posteriormente, realizamos el análisis de datos cualitativos sobre los comportamientos de los vecinos ante el problema del overtourism. Finalmente comparamos los resultados de la encuesta con los del análisis de prensa sobre los motivos por los que consideran que el turismo no beneficia a la ciudad.

\subsection{Análisis cuantitativo}

Ante la pregunta a los ciudadanos por su percepción de si el turismo aporta beneficios para Barcelona, el 81,5\% considera que sí, el 16,1\% considera que no, el $2 \%$ no sabe y el o,4 \% no contesta.

Si comparamos los datos de la encuesta de «Percepció del turisme» con los del «Baròmetre de Barcelona», se observan resultados similares. Ante la pregunta «¿Cuál cree que es el problema más grave que tiene la ciudad de Barcelona en estos momentos?», desde el año 2014 hasta el 2017 (figura 2), el turismo crece como problema principal de Barcelona, alcanzando en el mes de junio del 2017 el $19 \%$. Posteriormente comienza un descenso, siendo en junio del 2019 del 7,2 \% y en diciembre del 3,6\%.

\section{Figura 2}

Percepción del turismo como el problema más grave de Barcelona (\%)

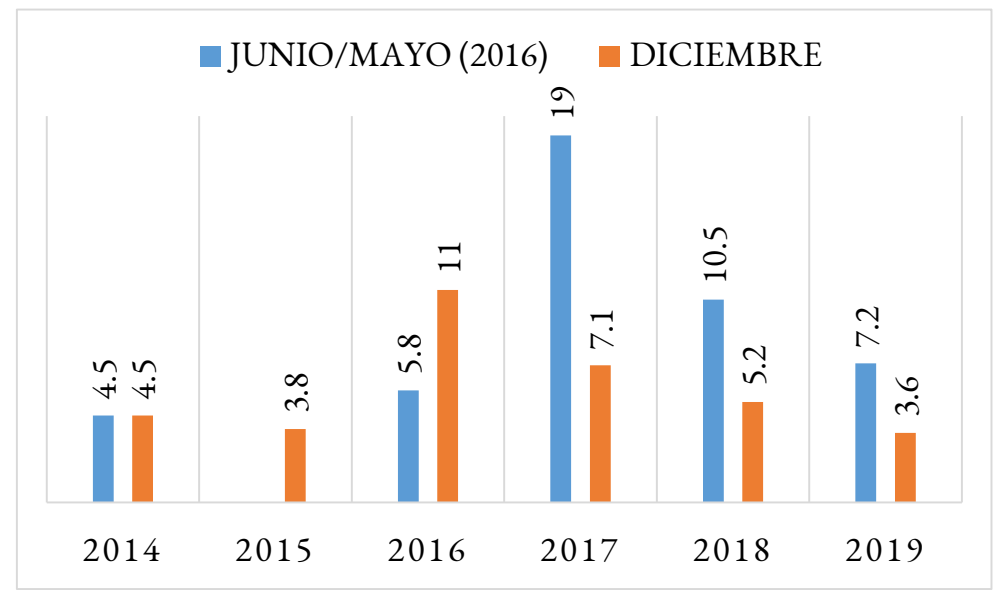

Fuente: Barómetros Barcelona 2014-2019 
Estos datos confirman la idea, presentada por Blanco-Romero, BlázquezSalom y Cánoves (2018) o de Russo y Scarnato (2018), de que las políticas de restricciones impuestas al alojamiento turístico, seguidas por los responsables de la ciudad, causaron un efecto importante en la percepción del turismo como un problema entre la población, aunque todavía insuficiente para algunos ciudadanos.

Respecto al perfil de las personas que consideran que el turismo no beneficia a la ciudad, si analizamos a nivel bivariado (tabla 1 ) los datos de los que contestan claramente que beneficia o perjudica, sin incluir los datos de los que no saben o no contestan y lo cruzamos con el distrito donde habitan, la asociación es significativa (o,ooo), existiendo diferencias de percepción según sea más o menos turístico el distritito donde se vive. Las zonas más turísticas, como son Ciutat Vella, Gràcia o Eixample, son las que consideran en mayor medida que el turismo no aporta beneficios para Barcelona, sino que la perjudica. El porcentaje de personas con espíritu crítico también es superior entre los que siempre vivieron en Barcelona, los que prefieren la lengua catalana y se incrementa con el nivel de estudios. Respecto a la relación laboral que el entrevistado mantuvo con el turismo en los últimos 12 meses, aunque es un poco superior la consideración de que perjudica a la ciudad entre los que no tienen relación laboral con el turismo, la diferencia con los que tienen relación laboral con el turismo no es estadísticamente significativa.

Con las variables que asocian significativamente a nivel bivariado, se realizó un análisis multivariable de ecuaciones estructurales generalizadas. ${ }^{4} \mathrm{En}$ un primer momento se incluyeron todas las variables contempladas en el modelo que, además, eran significativas estadísticamente en los análisis bivariados. Después de incluirlas en un modelo multivariable, resulta que la variable «siempre vivió en Barcelona» (siempreviv) no resultó significativa. Al no incluir dicha variable en el modelo, los resultados de ajuste también son mejores, bajando el AIC y el BIC, motivo por el que no incluimos dicha variable.

4 Aclaramos la necesidad de utilizar el modelo GSEM y no el SEM debido a que trabajamos con variables que no son de intervalo. 
Tabla 1

Percepción de la población de Barcelona del turismo, según las condiciones sociales de existencia

\begin{tabular}{|c|c|c|c|c|}
\hline & & \multicolumn{2}{|c|}{$\begin{array}{l}\text { Cree que el turismo beneficia o } \\
\text { perjudica la ciudad de Barcelona }\end{array}$} & \multirow[b]{2}{*}{ Total } \\
\hline & & Beneficia & Perjudica & \\
\hline \multirow[t]{4}{*}{ Distrito } & Otros & 85,7 & 14,3 & 100,0 \\
\hline & Gràcia & 80,4 & 19,6 & 100,0 \\
\hline & Eixample & 81,1 & 18,9 & 100,0 \\
\hline & Ciutat Vella & 79,0 & 21,0 & 100,0 \\
\hline \multirow{2}{*}{$\begin{array}{l}\text { Siempre vivió en Barcelo- } \\
\text { na }\end{array}$} & No & 85,5 & 14,5 & 100,0 \\
\hline & Sí & 80,5 & 19,5 & 100,0 \\
\hline \multirow[t]{4}{*}{ Nivel de estudios } & $\begin{array}{l}\text { Obligatorios no } \\
\text { finalizados }\end{array}$ & 94,1 & 5,9 & 100,0 \\
\hline & Obligatorios & 87,8 & 12,2 & 100,0 \\
\hline & Secundarios & 84,9 & 15,1 & 100,0 \\
\hline & Universitarios & 80,2 & 19,8 & 100,0 \\
\hline \multirow[t]{2}{*}{ Lengua prefiere entrevista } & Castellano & 88,6 & 11,4 & 100,0 \\
\hline & Catalán & 77,9 & 22,1 & 100,0 \\
\hline \multirow{2}{*}{$\begin{array}{l}\text { Relación laboral con el } \\
\text { turismo en los últimos } 12 \\
\text { meses }\end{array}$} & Sí & 85,0 & 15,0 & 100,0 \\
\hline & No & 83,3 & 16,7 & 100,0 \\
\hline
\end{tabular}

Fuente: elaboración propia

Los resultados del análisis multivariable pueden verse en la figura 3 y la tabla 2. Si nos fijamos en la columna de los OR puede verse que por cada persona que vive en otros distritos, 1,9 de los que viven en Ciutat Vella consideran que el turismo perjudica a la ciudad de Barcelona. En el caso del Eixample y de Gràcia son 1,3, debido a que también es menor la presión turística que en Ciutat Vella, pero mayor que en otros distritos.

En el caso de las personas que suelen utilizar la lengua catalana y la prefirieron para hacer la entrevista, por cada persona que utiliza el castellano, tenemos 2,6 de los que utilizan el catalán que consideran que el turismo perjudica Barcelona. De ahí puede derivarse una relación entre el apego a la cultura y el espíritu crítico respecto al turismo. 
El nivel de estudios también está directamente relacionado con el espíritu crítico, de modo que a medida que se incrementan los estudios se incrementa la conciencia de que el turismo perjudica Barcelona. Por cada persona que no tiene estudios tenemos 2,2 de los que tienen estudios obligatorios que consideran que el turismo perjudica Barcelona, 2,5 de estudios medios y 3,2 de estudios superiores. El nivel de estudios ejerce un efecto directo y otro indirecto mediante el empleo de la lengua catalana, de modo que con el incremento del nivel de estudios también se incrementa el uso de la lengua catalana y el espíritu crítico sobre el turismo.

Figura 3

Representación de las variables que asocian significativamente y valores de los coef.

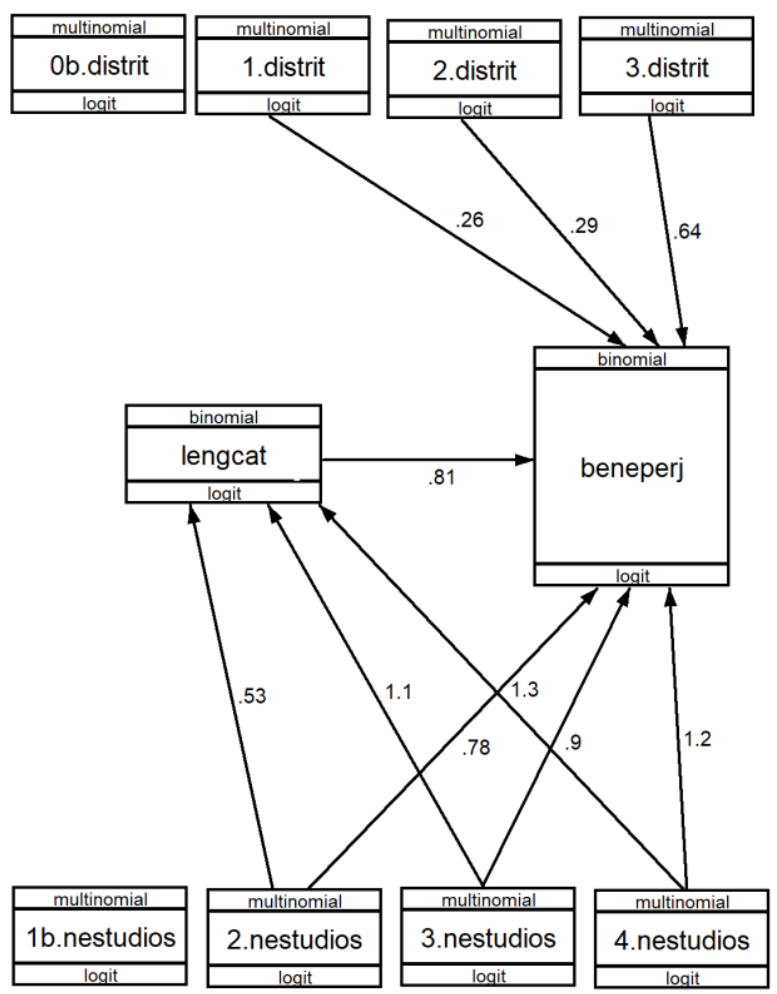

Fuente: elaboración propia 
Tabla 2

Valores del análisis GSEM

\begin{tabular}{|c|c|c|c|c|c|c|c|c|}
\hline & & Coef. & OR & $\begin{array}{l}\text { Std. } \\
\text { Err }\end{array}$ & $\mathrm{z}$ & $\mathrm{P}>\mathrm{z}$ & $\begin{array}{l}{[95 \%} \\
\text { Interval] }\end{array}$ & Conf. \\
\hline \multicolumn{9}{|l|}{ beneperj <- } \\
\hline \multirow[t]{4}{*}{ distrit } & \multicolumn{2}{|l|}{ Otros distritos } & 1 & & & & & \\
\hline & Gràcia & 0,256 & 1,292 & 0,121 & 2,110 & $0,035^{*}$ & 0,019 & 0,493 \\
\hline & Eixample & 0,287 & 1,332 & 0,120 & 2,390 & $0,017^{*}$ & 0,052 & 0,522 \\
\hline & Ciutat Vella & 0,636 & 1,889 & 0,108 & 5,910 & $0,000^{* * *}$ & 0,425 & 0,847 \\
\hline \multirow[t]{2}{*}{ lengcat } & No & & 1 & & & & & \\
\hline & Sí & 0,813 & 2,254 & 0,082 & 9,860 & $0,000^{* * *}$ & 0,651 & 0,975 \\
\hline \multirow[t]{4}{*}{ nestudios } & \multicolumn{2}{|c|}{ Obligatorios no finalizados } & 1 & & & & & \\
\hline & Obligatorios & 0,777 & 2,175 & 0,530 & 1,470 & 0,143 & $-0,262$ & 1,816 \\
\hline & Secundarios & 0,897 & 2,452 & 0,524 & 1,710 & 0,087 & $-0,131$ & 1,925 \\
\hline & Universitarios & 1,171 & 3,226 & 0,523 & 2,240 & $0,025^{*}$ & 0,146 & 2,197 \\
\hline \multicolumn{9}{|l|}{ lengcat $<-$} \\
\hline \multirow[t]{4}{*}{ nestudios } & \multicolumn{2}{|c|}{ Obligatorios no finalizados } & 1 & & & & & \\
\hline & Obligatorios & 0,531 & 1,701 & 0,293 & 1,810 & 0,070 & $-0,043$ & 1,106 \\
\hline & Secundarios & 1,128 & 3,088 & 0,288 & 3,910 & $0,000^{* * *}$ & 0,562 & 1,693 \\
\hline & Universitarios & 1,317 & 3,733 & 0,288 & 4,580 & $0,000^{* * *}$ & 0,753 & 1,881 \\
\hline
\end{tabular}

Fuente: elaboración propia

Se les preguntó a los vecinos críticos el motivo por el que consideran que el turismo no beneficia a la ciudad. Podían contestar hasta cuatro motivos. Si sumamos las veces que contestaron cada motivo (figura 4 ), resulta que el motivo más indicado es la masificación $(55,4 \%$ ), seguido del incivismo de los turistas (39,3\%), la subida del precio del alquiler, la pérdida de esencia de vida en los barrios, la subida general de precios, el turismo low cost / de baja calidad, el desalojo de los barceloneses de su ciudad, que el turismo solo beneficia a unos pocos y el ruido provocado. 
Figura 4

Por qué el turismo no beneficia la ciudad

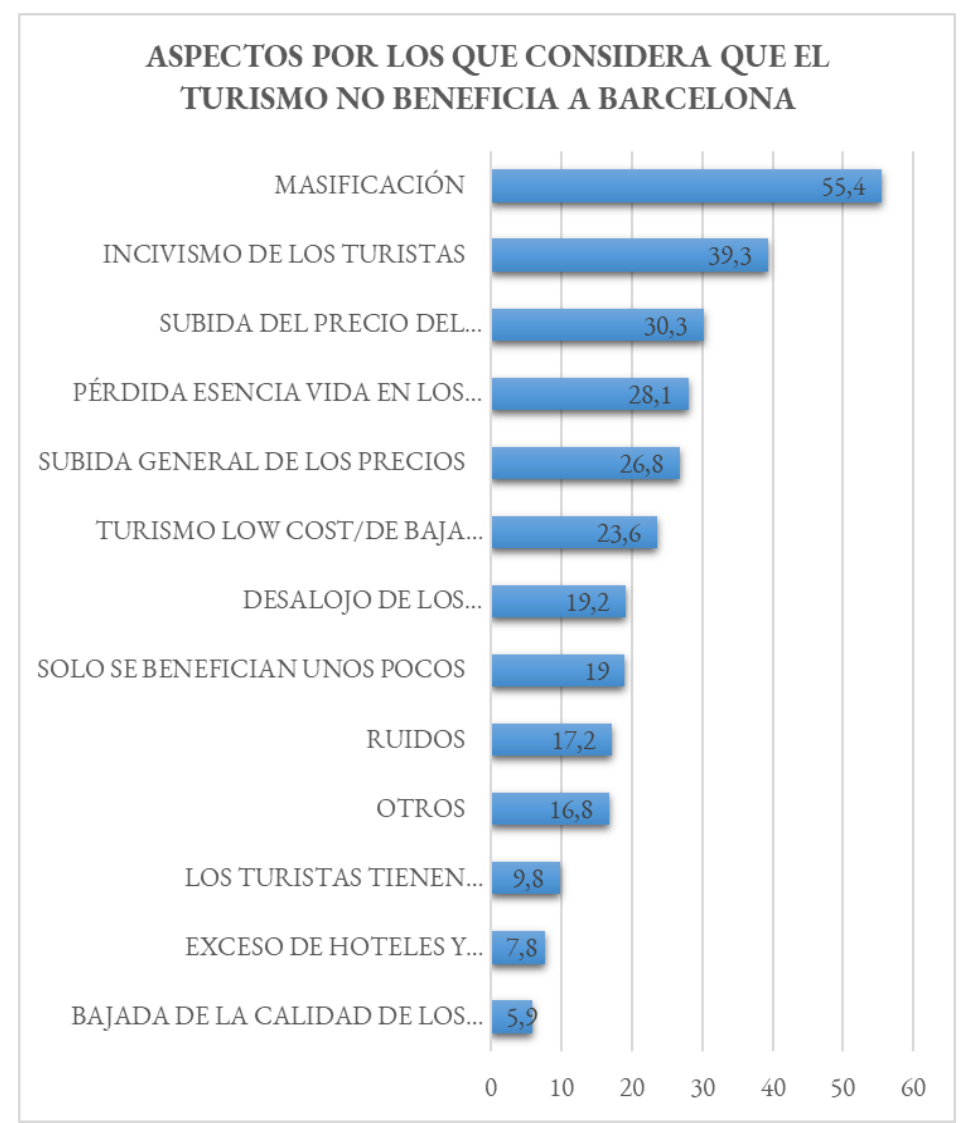

Fuente: elaboración propia

\subsection{Análisis cualitativo}

Después de un primer análisis descriptivo de recuento de palabras, pasamos a comprender la problemática mediante el análisis del contexto de esas palabras y marcamos citas (incidentes), codificamos esas citas, establecemos coocurrencias, agrupamos los códigos en categorías, analizamos esas categorías como teoría sustantiva y elaboramos posteriormente una teoría formal. Al final apuntamos también las hipótesis para seguir trabajando en futuras investigaciones. 


\subsubsection{Recuento de palabras}

De los artículos indicados que tomamos como base, en un primer momento realizamos un análisis descriptivo, consistente en un recuento de las palabras. Como se pude observar en la tabla 3 y la figura 5 , las palabras que más aparecen en los medios son las siguientes: vecinos, turismo, barrio, Barceloneta, turistas, Barcelona, pisos (turísticos), ciudad, playa, protestas y ayuntamiento. En el entorno de todas estas palabras aparecen una serie de contenidos, asociados a ellas, que es necesario analizar.

Tabla 3

Recuento de palabras

\begin{tabular}{|l|l|}
\hline vecinos & 64 \\
\hline turismo & 51 \\
\hline barrio & 48 \\
\hline Barceloneta & 46 \\
\hline turistas & 44 \\
\hline Barcelona & 42 \\
\hline pisos & 34 \\
\hline ciudad & 33 \\
\hline playa & 30 \\
\hline turisticos & 23 \\
\hline también & 21 \\
\hline protesta & 17 \\
\hline ayuntamiento & 17 \\
\hline todo & 15 \\
\hline personas & 13 \\
\hline euros & 12 \\
\hline millones & 12 \\
\hline alquiler & 11 \\
\hline verano & 10 \\
\hline
\end{tabular}

\begin{tabular}{|l|l|}
\hline barrios & 10 \\
\hline jóvenes & 10 \\
\hline mar & 9 \\
\hline calle & 9 \\
\hline otros & 9 \\
\hline puede & 9 \\
\hline capital & 9 \\
\hline problema & 9 \\
\hline turístico & 9 \\
\hline asociación & 9 \\
\hline manifestantes & 9 \\
\hline imagen & 8 \\
\hline quejas & 8 \\
\hline catalana & 8 \\
\hline ilegales & 8 \\
\hline vivienda & 8 \\
\hline actividad & 8 \\
\hline plataforma & 8 \\
\hline visitantes & 8 \\
\hline & \\
\hline
\end{tabular}

\begin{tabular}{|l|l|}
\hline apartamentos & 8 \\
\hline barceloneses & 8 \\
\hline zona & 7 \\
\hline arena & 7 \\
\hline grupo & 7 \\
\hline calles & 7 \\
\hline precio & 7 \\
\hline asegura & 7 \\
\hline durante & 7 \\
\hline gestión & 7 \\
\hline hoteles & 7 \\
\hline economía & 7 \\
\hline pancarta & 7 \\
\hline queremos & 7 \\
\hline pancartas & 7 \\
\hline turística & 7 \\
\hline especulación & 7 \\
\hline movilización & 7 \\
\hline manifestación & 7 \\
\hline & \\
\hline & \\
\hline
\end{tabular}

Fuente: elaboración propia 
Figura 5

Nube de palabras de los 12 documentos

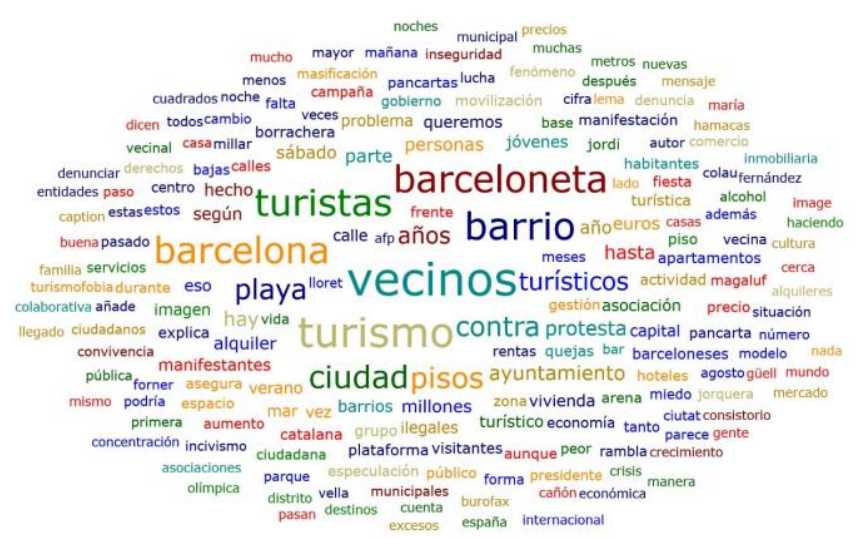

Fuente: elaboración propia

\subsubsection{Incidencias y códigos}

Realizamos un análisis de los documentos, centrados en tres grandes aspectos: los problemas asociados al overtourism que repercuten de forma negativa en los ciudadanos, en el sector turístico y en la sociedad; los actores implicados, y las demandas vecinales.

Después de leer los artículos, realizamos las citas que consideramos oportunas en Atlas.ti - siguiendo los tres grandes aspectos indicados-, las codificamos y juntamos los códigos en grupos (categorías). La lista de códigos resultantes se puede ver en la figura 6. Pusimos en diferentes colores el tipo de código en relación con las preguntas de investigación realizadas. Los problemas los dividimos en cuatro grandes grupos: los éticos, que están relacionados con el comportamiento incívico de los turistas (en rojo); los socioeconómicos, que están relacionados con los problemas que el turismo masivo tiene para los ciudadanos, el sistema turístico y la ciudad (en amarillo); los relacionados con los actores que intervienen en los problemas indicados (en naranja), y los relacionados con las protestas y propuestas que realizan los vecinos (en verde). El factor ambiental apenas tiene impacto. En todo caso (más adelante) formamos una categoría incluyendo dos códigos: $a$ ) «ruido y suciedad» y $b$ ) «pérdida de autenticidad y disneyficación» (no nombran deterioro del patrimonio ambiental ni de la «cultura culta» reconocida institucionalmente). 
Figura 6

Códigos resultantes del análisis de los artículos

- Abolición pisos turísticos

- Alianza grandes poderes (financiero, político)

- Borrachera y droga

- Capacidad de carga: impiden caminar

- Crecimiento ilimitado

- Desenfreno moral, incivismo

- Desnudez

- Economía colaborativa, AirBnb

- Economía del monocultivo turístico

- Empresarios corruptos

- Empresarios responsables

- Escándalo

- Falta de regulación laboral, intrusismo

- Gentrificación, subida alquiler

- Imagen negativa, libertinaje

- Indignación

- Información a empresarios

- Información a las autoridades

- Información a los turistas

- Insoportable para los habitantes

- Insostenible para la ciudad

- Instituciones políticas, técnicas, académicas

- Integración social

- Manifestación-protesta

- Negocios ilegales
- No respeto reglas convivencia

- No turismofobia, no mezclar acontecimientos

- Ofensa moral

- Ordenación

- Organizaciones para el desenfreno

- Peleas, inseguridad, miedo

- Perder la cabeza

- Pérdida autenticidad, disneyficación

- Pérdida de capital social de los vecinos

- Perjudica la vida de los vecinos

- Pesadilla

- Privatización del espacio público

- Relaciones sexuales a la vista

- Repercusión negativa economía ciudadana

- Riesgo para la vida, tragedia, muerte

- Ruido, suciedad

- Sanciones

- Solo se benefician unos pocos

- 'Turismo incívico

- Turismo low cost

- Turismo masificado (no solo por número, sino por mala gestión y comportamiento)

- 'Turismo responsable

- Turistas irresponsables

- Vecinos

Fuente: elaboración propia

Cada código está fundamentado en sus correspondientes citas. Ante la imposibilidad de comentar en el espacio de un artículo todos ellos, tomamos un código, el de «borrachera y droga».5 En la sociedad actual existe un grave problema con el consumo de drogas de distinto tipo, con múltiples causas (Di Chiara, 1995). El turismo, aunque no es la causa, muchas veces se convierte en el espacio para la borrachera y el consumo de drogas (Uriely y Belhassen, 2006). Y, en ciertos casos, incluso la droga puede convertirse en un recurso para la atracción turística (Wen, Meng, Ying, Qi y Lockyer, 2018).

5 Hay que aclarar que uno de los artículos que salía en los primeros lugares de Google y que incluimos en el análisis se refiere no solo a Barcelona, sino a toda España, aunque después se centra en algunas poblaciones de la costa del Mediterráneo y, en específico, también en Barcelona. Algunos de los datos que proporciona son del contexto, pero los incluimos por lo ilustrativos que son de la situación de este tipo de turismo que denuncian los vecinos. 
Figura 7

\section{Citas asociadas al código «Borrachea y droga»}

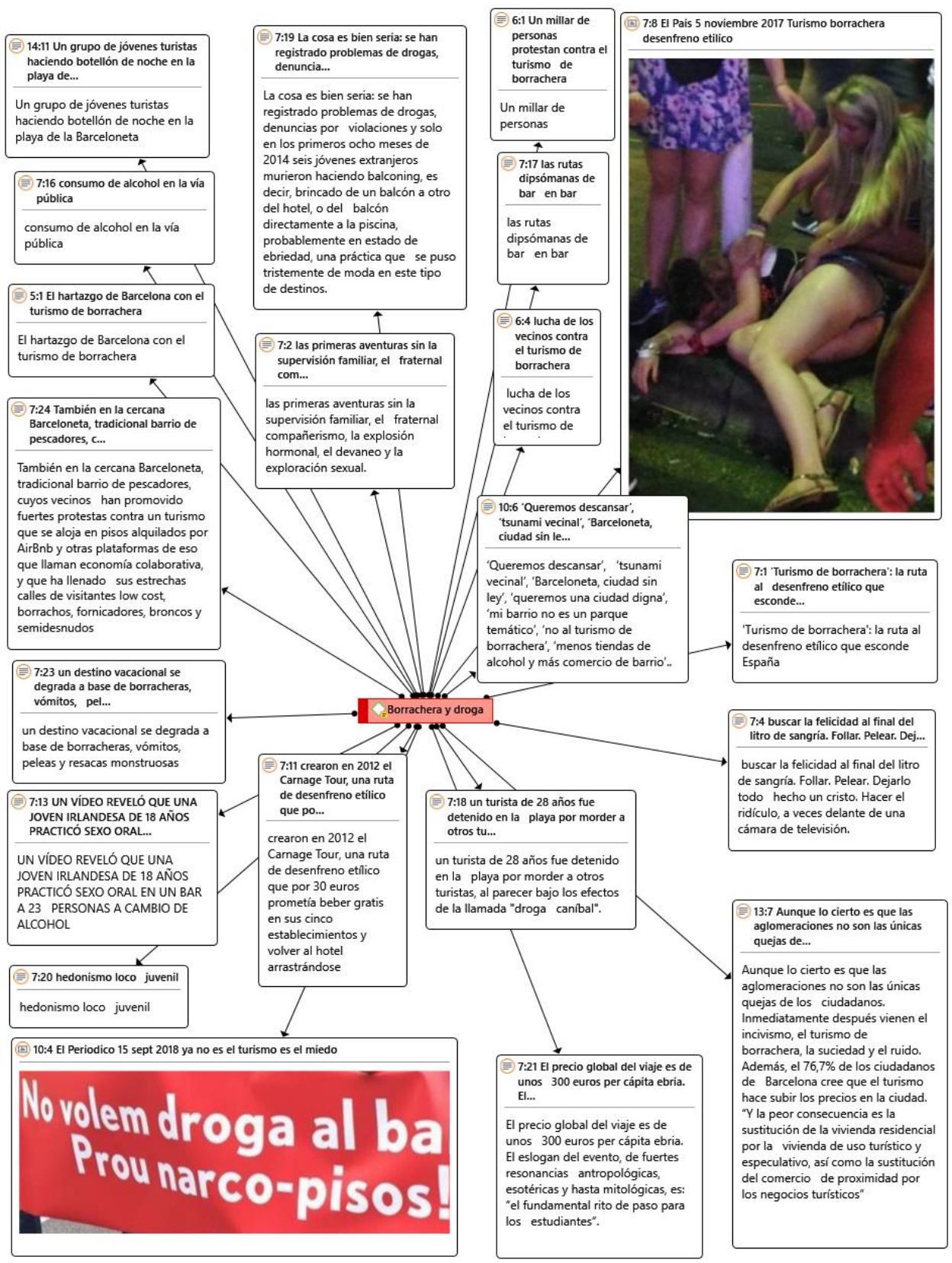

Fuente: elaboración propia 
Esta práctica puede beneficiar a los actores que hacen negocio con los turistas, pero perjudica a la sociedad en su conjunto. Podemos ver todas las citas a las que está asociado (figura 7). En una de las citas podemos leer: «La cosa es bien seria: se han registrado problemas de drogas, denuncias por violaciones». Sobre la imagen del destino y su repercusión dicen: «Un destino vacacional se degrada a base de borracheras, vómitos, peleas y resacas monstruosas».

\subsubsection{Coocurrencias}

Podemos analizar bien las coocurrencias de un determinado código con todos los otros códigos de su misma problemática (categoría) o bien las coocurrencias de un determinado código con todos los otros códigos del estudio.

Como ejemplo, las coocurrencias de «borrachera y droga» con todos los otros códigos del estudio son representados en la tabla 4. Cuando se da «borrachera y droga», también se dan al mismo tiempo las siguientes actividades incívicas: desnudez en público — personas que van al supermercado totalmente desnudas y tienen que ser expulsadas por los propietarios ante el asombro de los vecinos-; peleas e inseguridad que hacen cundir el pánico entre los vecinos; riesgos para la vida, tragedias; o la pérdida de autenticidad del barrio, es decir, que el barrio se convierte en una suerte de Disney. Es entonces cuando los vecinos se muestran en contra del turismo existente y piden un turismo responsable.

Tabla 4

Coocurrencias del código «Borrachera y droga» con otros códigos del estudio en general

\begin{tabular}{|l|l|}
\hline & Borrachera y droga \\
\hline Capacidad de carga: impiden caminar & 1 \\
\hline Desnudez & 1 \\
\hline Economía colaborativa, Airbnb & 1 \\
\hline Economía del monocultivo turístico & 1 \\
\hline Empresarios corruptos & 2 \\
\hline Gentrificación, subida alquiler & 1 \\
\hline Organizaciones para el desenfreno & 1 \\
\hline Peleas, inseguridad, miedo & 3 \\
\hline Pérdida autenticidad, disneyficación & 1 \\
\hline
\end{tabular}




\begin{tabular}{|l|l|}
\hline Relaciones sexuales a la vista & 6 \\
\hline Riesgo para la vida, tragedia, muerte & 4 \\
\hline Ruido, suciedad & 1 \\
\hline Turismo low cost & 3 \\
\hline $\begin{array}{l}\text { Turismo masificado (no solo por número, sino por mala gestión y } \\
\text { comportamiento) }\end{array}$ & 1 \\
\hline Turismo responsable & 2 \\
\hline Turistas irresponsables & 3 \\
\hline Vecinos & 3 \\
\hline
\end{tabular}

Fuente: elaboración propia

\subsubsection{Categorías}

Unimos los códigos semejantes, formando categorías. Las cinco grandes categorías que formamos son: comportamiento incívico, insostenibilidad socioeconómica, insostenibilidad medioambiental —aunque son escasas las referencias-, actores y demandas ciudadanas de turismo responsable (figura 10).

Surge así un tema ético en turismo: la reclamación de los ciudadanos de que se respete su voluntad y sus normas de convivencia. Es necesario, por lo tanto, tener en cuenta la máxima de MacCannell de que la industria turística necesita tener en cuenta la voluntad de los actores externos a la industria que viven en las zonas turísticas (MacCannell, 2011; López-González, 2018a), que no estaba previsto de forma explícita en las teorías del desarrollo sostenible como un factor separado y que, dado su peso, es necesario introducir. Sin embargo, el factor del medioambiente, natural o cultural, tiene poco peso, no siendo nombrado en las encuestas a residentes, ni en los artículos periodísticos. Nosotros lo incluimos, pero con unos códigos escasos como son la contaminación natural («ruido, suciedad») y el medio cultural (la «pérdida de autenticidad» y la «disneyficación del espacio»).

Entre los códigos de la categoría «comportamiento incívico», el código central para incivismo es el de «borrachera y droga». Otros códigos muy relacionados con el de «borrachera y droga» son el de «relaciones sexuales a la vista», «peleas», «inseguridad» o «miedo». Pero también ocupan un papel importante el «desenfreno moral e incivismo», el cual no es algo libre de los turistas, sino que está organizado por redes. Eso, a su vez, se relaciona con riesgo para la vida. 
Todo esto supone ruido que no deja dormir, suciedad, mala imagen de la ciudad y de los vecinos y acaba por ser dañino para la imagen que los vecinos tienen de su ciudad y de su ambiente, pero también para la imagen exterior de la ciudad, a la que ya no querrán venir los turistas que dejan más beneficios y menos contaminación. Los grandes mayoristas llevarán esos turistas a otros lugares que estén menos masificados y donde se respeten las normas cívicas. Esto crea en la población una situación de anomia, de malestar. Hay personas que ya indicaron su intención de marcharse a vivir a otra ciudad. La gentrificación es por motivos económicos, pero también por degradación de la calidad de vida, e incluso porque sienten miedo viendo peleas en la calle. a veces con arma blanca.

En la categoría «insostenibilidad socioeconómica», el código que tiene mayor peso es «gentrificación y la subida de los alquileres». Los vecinos son expulsados mediante estrategias económicas. Viviendas de las que se echa a los vecinos al pedirles un precio del alquiler que para ellos es impagable, no para los turistas, que solo vienen unos días, se van y vienen otros, y así se hacen grandes negocios. En otros casos ya ni siquiera se les presenta la posibilidad de un alquiler más elevado, sino que simplemente se les hecha para disponer del inmueble para grandes recipientes de apartamentos turísticos.

Pero los vecinos no solo se preocupan por su vivienda, su domicilio, sino que también lo hacen por los espacios públicos que son privatizados por empresas para hacer negocio, como son las playas con las hamacas, las plazas con terrazas de los bares, los puertos pesqueros para dejar espacio para los turistas y su ocio. A ellos no les queda donde tomar el sol, donde hablar con los vecinos, donde salir a comunicarse y a disfrutar de su cultura.

En la categoría «demandas de turismo responsable» (figura 8), priman las manifestaciones de protesta, aunque también la información transmitida a turistas, empresarios y autoridades, en las que se demanda la ordenación del sector, mediante ordenanzas del ayuntamiento prohibiendo determinados actos incívicos, pero también perseguir a empresarios que llevan a cabo actividades económicas ilegales. Aclaran que están a favor del turismo, pero en contra del turismo masivo incívico e insostenible que destroza su calidad de vida. 
Figura 8

\section{Categoría «Demandas ciudadanas turismo responsable»: códigos y citas asociadas}

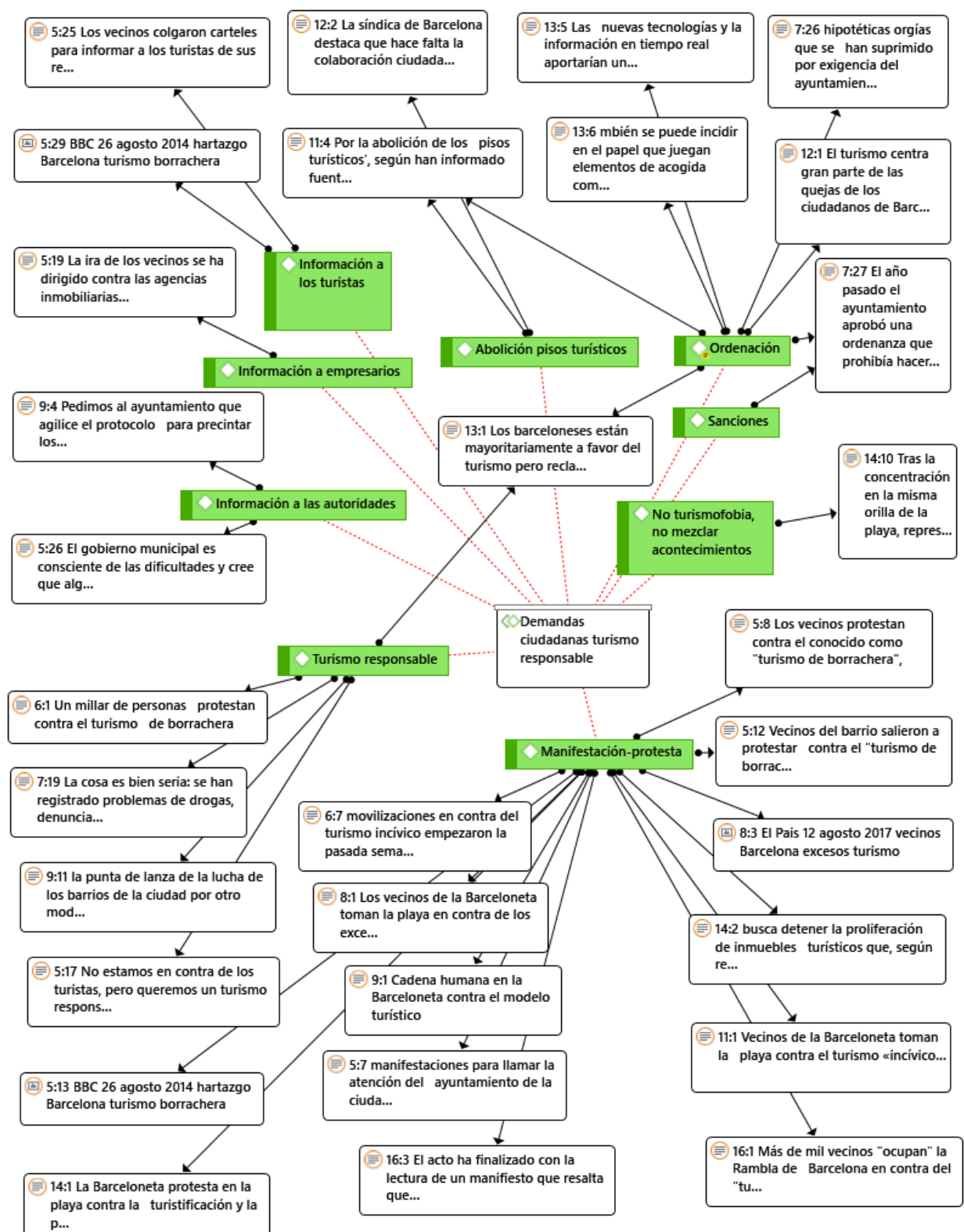

Fuente: elaboración propia 


\subsubsection{Teoría formal}

Una teoría adecuada para entender las reacciones de la población ante el turismo puede ser la teoría del intercambio social (Cropanzano y Mitchell, 2005; Harrill, 2004; Musinguzi, 2019; Blau, 1964). Sin embargo, esta teoría aplicada de forma simplista, en tanto que a veces toma un intercambio económico como único factor, puede no explicar toda la problemática, de modo que es necesario completarla con una visión de sistemas complejos (Miramontes, 2000; Baggio, 2013) y comportamiento ético (Fennell, 2006; López-González, 2018b; MacCannell, 2011). Como indican Andereck, Valentine, Knopf y Vogt (2005), una teoría del intercambio social que solo prima lo económico hay que completarla con otra que incluya lo social y los valores: «esta teoría incluye elementos basados en el mercado y la economía, al igual que la teoría del intercambio social, pero también permite elementos menos cuantificables para tomar decisiones, como valores y creencias» (Andereck, Valentine, Knopf y Vogt, 2005: 1073).

En la actividad turística influyen muchos factores y muchos actores con distintos intereses (figuras 9 y 10 ). El turismo tiene repercusiones positivas y negativas en cada factor, dándose la posibilidad de que las positivas en un factor para un actor resulten negativas para otros actores (Andereck, Valentine, Knopf y Vogt, 2005; Aguiló y Rosselló, 2005). Si no existe acuerdo, hay que analizar qué pesa más en la decisión final del modelo turístico a implantar, si solo el factor económico - base principal de la teoría del intercambio- o los factores sociales, culturales e incluso ambientales. Si tenemos en cuenta la teoría de la posmodernidad, los últimos factores pueden pesar más que los primeros. En estos momentos se produce un intercambio económico en el cual los vecinos no participan, dicen: «Hablan de los millones que dejan los visitantes y quizá tengan razón, pero ese dinero, ¿en manos de quién queda? Aquí solo vemos la precariedad laboral de los trabajadores del sector. Contratos basura en los que pagan miseria». Intervienen alianzas entre los grandes poderes financieros y las élites políticas (figura 9). Y el dinero va a parar a empresarios corruptos a quienes no les importa lucrarse con la salud de los propios turistas, expulsando a los empresarios locales. Pero, en todo caso, el factor al que más peso le dan los vecinos es el factor ético relacionado con la convivencia. 
Figura 9

\section{Relación entre los códigos empresarios corruptos, alianza de grandes poderes (financiero, político) y solo se benefician unos pocos}

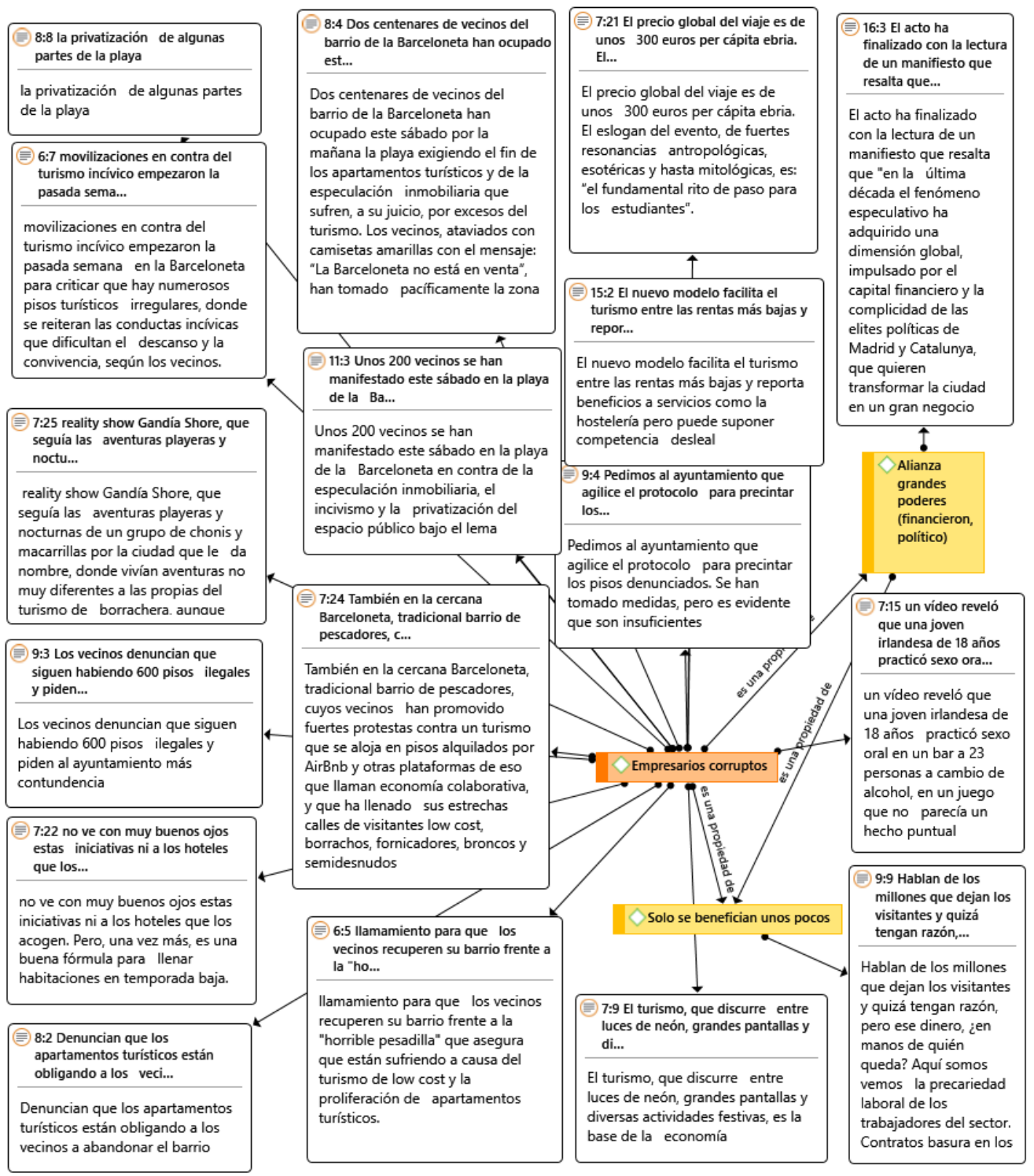

Fuente: elaboración propia 
Así, la teoría del intercambio tiene que emplearse desde la perspectiva de la complejidad y del código ético (figura 8). Actores con asimetría de poder entre ellos (figura 9) -vecinos, empresarios tradicionales, nuevos empresarios de plataformas, grandes mercados financieros, partidos políticos, turistastienen distintos intereses que afectan a la toma de decisiones de cada uno de los factores (económico, social, medioambiental y de conducta ética). Lo que reclaman los vecinos es que se tenga en cuenta sus intereses y se haga desde la perspectiva ética (Fennell, 2006; López-González, 2018b; MacCannell, 2011). Las nuevas estrategias que les afectan de forma negativa no son las de una economía colaborativa basada en proveedores que pasan de ser empresas a meros individuos que toman los distintos servicios ofrecidos a los turistas como una actividad extra, basándose en tecnologías de la información (plataformas) para conectar oferta y demanda. Lo que les afecta negativamente es el proceso de mercantilización neoliberal a través de las plataformas que pervirtió su espíritu originario de la economía colaborativa. Tal y como señala Huete, «a medida que los fondos de capital riesgo se hicieron con el control de las plataformas intermediarias, el espíritu original "colaborativo" fue pervertido» (Huete, 2019: 306).

Quedan como hipótesis pendientes de contrastar en futuras investigaciones si los vecinos de las grandes ciudades masificadas por el turismo tienen o no conciencia sobre los problemas ambientales que afectan al patrimonio natural y la gran cultura. Al menos en este caso no lo detectamos.

También resultó importante el aspecto ético, por lo que es necesario comprobar en futuras investigaciones si los temas de ética y civismo tienen un peso fundamental en el caso de las denuncias y manifestaciones contra el overtourism. 
Figura 10

Teoría formal central y relación con las categorías sustantivas

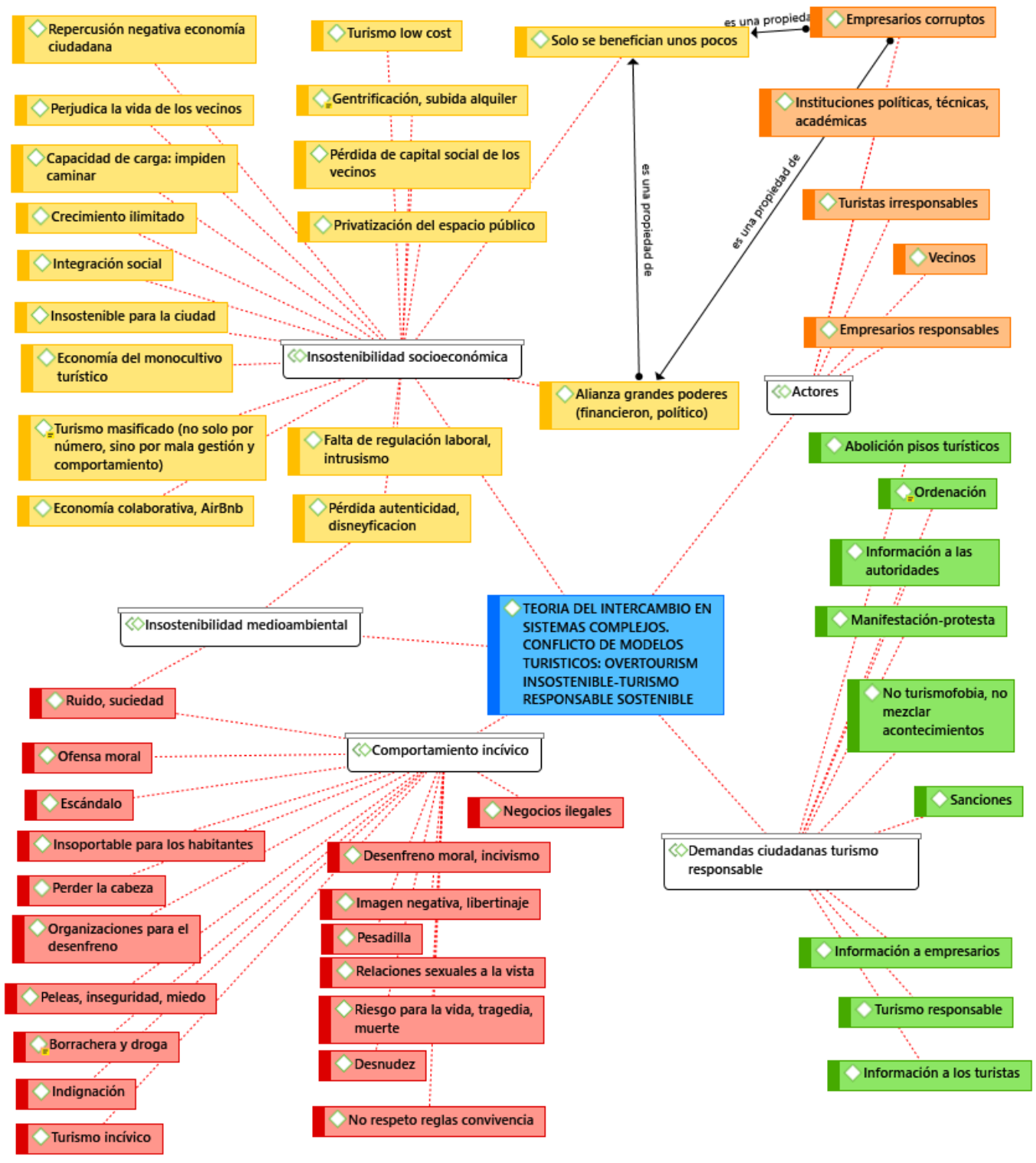

Fuente: elaboración propia 


\section{CONCLUSIONES}

Como conclusiones vamos a intentar dar respuesta de forma resumida a los objetivos-preguntas que nos marcamos al principio de la investigación. Este artículo está basado en encuestas de opinión a las personas de Barcelona y en artículos de prensa, ambos importantes para analizar el problema planteado. No obstante, para seguir profundizando en él, es recomendable contar con otras voces.

El porcentaje de población crítica con el modelo de overtourism se eleva a un $16 \%$ de los barceloneses, similar a los resultados de los que consideran el turismo un problema importante de Barcelona (figura 2, 19\% en junio del año 2017, cuando alcanza el porcentaje más elevado), lo cual es un problema significativo, pero que tampoco podemos globalizar. El perfil las personas con actitud crítica es el de personas que habitan en los distritos más turísticos, con elevada formación $\mathrm{y}$ con apego $\mathrm{y}$ vinculación a la comunidad (figura 3 y tabla 2).

Las razones que manifiestan están relacionadas con la sostenibilidad, pero con dos apreciaciones importantes. Una de ellas es que no nombran los factores del medioambiente natural ni cultural de la alta cultura, pero sí de la cultura de identidad del barrio. Otra, que el factor socioeconómico tiene mucha importancia y cobra especial relevancia el factor cívico, el respeto a las normas de convivencia y decoro social que rompen los turistas irresponsables, acuciados por los empresarios corruptos que les manejan para aprovecharse de ellos. Estas manifestaciones son similares tanto en las respuestas recogidas en la encuesta a la población como en el contenido de los artículos de prensa (figuras 4 y 6).

En este problema están implicados distintos actores: los turistas, los vecinos, los empresarios y las instituciones. Hay que diferenciar entre los empresarios tradicionales y los grandes empresarios que se implantaron en la actualidad. Los tradicionales tienen pequeños negocios en el barrio y son defendidos por los vecinos, que los ven como aliados y como una víctima más del modelo de turismo existente. Los grandes empresarios que se implantaron en la actualidad están aliados con los grandes poderes financieros y políticos que manejan la situación al más alto nivel (figura 9). Los ciudadanos reclaman un cambio de estrategia que tenga en cuenta los vínculos de la sociedad y no solo los grandes negocios económicos. Como MacCannell (2011) reclama, buscan 
que no decline la relación y la confianza institucional. El turismo no puede guiarse solo por intereses comerciales puramente egoístas. Si se hace, terminará por fracasar al no ser querido por la sociedad.

Las estrategias que siguen los vecinos para mostrar su descontento (figura 8) son de tres grandes tipos: $a$ ) manifestaciones de protesta en las calles y en la playa; $b$ ) información a los propios turistas - por ejemplo, con pancartas en los balcones-, a los empresarios y a las autoridades, y c) reclamaciones formales ante el síndico. No obstante, no siempre quieren realizar denuncias detalladas de los pisos ilegales. Desean que lo hagan las instituciones a través de los cauces formales establecidos. No quieren que se les identifique con las protestas que conllevan violencia y que se dieron en llamar «turismofobia» (Huete y Mantecón, 2018) por los medios de comunicación. Proponen a las instituciones que aprueben normas de comportamiento para vecinos y empresas que llevan a cabo actividades ilegales; desean que les impongan sanciones. Y no tienen una estrategia para los grandes poderes financieros que cuentan con el apoyo político al más alto nivel.

Después de realizar este análisis se puede considerar que la teoría del intercambio social es básica para entender el conflicto existente entre los vecinos y el modelo turístico de masas. El fondo de dicho conflicto tiene que analizarse desde la teoría del intercambio, pero no de manera simplista, sino teniendo en cuenta la complejidad de un sistema con distintos autores y diferentes intereses para cada uno de los factores de la sostenibilidad, así como el fundamento ético que debería respetarse.

A estos problemas, en la actualidad, se puede sumar uno nuevo debido a la pandemia causada por la COVID-19. Por una parte, ha supuesto un descenso del turismo, lo cual aminora ciertos excesos del overtourism. Pero, por otra parte, la llegada de turistas puede conllevar recelos por parte de los habitantes, al considerar que los turistas pueden traer el virus ${ }^{6}$ y contribuir a su difusión mediante comportamientos incívicos que no respeten las normas establecidas para su gestión. También puede constituir un problema para los trabajadores del sector debido a su trabajo precario e inseguro ante el virus. De momento, no podemos dar datos concluyentes, pero ya se han producido las primeras manifestaciones de trabajadores preocupados por falsos sellos de calidad que les pueden poner en riesgo (Macedo, 2020). Hay que estar atentos al futuro.

Aunque no tenemos noticias de Barcelona, en otras zonas lugareños y turistas se han peleado por acusaciones de contagio de virus (Miser, 2020). 


\section{BIBLIOGRAFÍA}

Aguiló, Eugeni y Rosselló, Jaume (2005). Host community perceptions a cluster analysis. Annals of Tourism Research, 32(4), 925-941.

Ajuntament de Barcelona (2017). Percepció del Turisme a Barcelona 2017. Recuperado de: https://ajuntament.barcelona.cat/es/informacionadministrativa/registro-de-encuestas-y-estudios-de-opinion [Consultado el 3 de junio de 2019].

Ajuntament de Barcelona (2019). Barometre de Barcelona. Recuperado de: https://ajuntament.barcelona.cat/es/informacionadministrativa/registro-de-encuestas-y-estudios-de-opinion [Consultado el 15 de julio de 2020].

Almeida-García, Fernando, Cortés-Macías, Rafael, Balbuena-Vázquez, Antonia e Hidalgo, María del C. (2020). New Perspectives of Residents' Perceptions in a Mature Seaside Destination. Sustainability, $12(10), 4183$.

Alrwajfah, Moayad M., Almeida-García, Fernando y Cortés-Macías, Rafael (2019). Residents' perceptions and satisfaction toward tourism development: A case study of Petra Region, Jordan. Sustainability, 11(7), 1907 .

Andereck, Kathleen L., Valentine, Karin M., Knopf, Richard C. y Vogt, Christine A. (2005). Residents' perceptions of community tourism impacts. Annals of tourism research, 32(4), 1056-1076.

Baggio, Rodolfo (2013). Studying complex tourism systems: a novel approach based on networks derived from a time series. XIV International Academic Conference on Economic and Social Development, Moscow, abril 2-5, 2013. Recuperado de: https://arxiv.org/abs/1302.5909 [Consultado el 12 de mayo de 2020].

Belisle, Francois J. y Hoy, Don R. (1980). The perceived impact of tourism by residents a case study in Santa Marta, Colombia. Annals of Tourism Research, 7(1), 83-101. 
Blanco-Romero, Asunción, Blázquez-Salom, Marcià y Cànoves, Gemma (2018). Barcelona, Housing Rent Bubble in a Tourist City. Social Responses and Local Policies. Sustainability, 10(6), 2043.

Blau, Peter (1964). Exchange and power in social life. New York: John Wiley.

Butler, Richard W. (1980). The concept of a tourist area cycle of evolution: implications for management of resources. The Canadian Geographer, 24(1), 5-12.

Cardona, José R. (2012). Actitudes de los residentes hacia el turismo en destinos turísticos consolidados: El caso de Ibiza. Tesis doctoral. Palma: Universitat de les Illes Balears. Recuperado de : https://www.tdx.cat/handle/10803/104266\#page=1 [Consultado el 12 de mayo de 2020].

Cropanzano, Russell y Mitchell, Marie S. (2005). Social exchange theory: An interdisciplinary review. Journal of Management, 31(6), 874900.

Di Chiara, Gaetano (1995). The role of dopamine in drug abuse viewed from the perspective of its role in motivation. Drug and alcohol dependence, $38(2), 95^{-137}$.

Doxey, George V. (1975). irritants: Methodology and research inferences. En Proceedings of the Sixth Annual Conference of the Travel Research Association. San Diego, CA: The Travel Research Association.

Fennell, David A. (2006). Tourism ethics. Clevedon: Channel View Publications.

Haralambopoulos, Nicholas y Pizam, Abraham (1996). Perceived Impacts of Tourism: The Case of Samos. Annals of Tourism Research, 23(3), 503-526.

Harrill, Rich (2004). Residents' attitudes toward tourism development: A literature review with implications for tourism planning. Journal of planning literature, 18(3), 251-266. 
Hernández Sampieri, Roberto, Fernández Collado, Carlos y Baptista, Pilar (2014). Metodología de la Investigación. México: McGrawHill.

Huete, Raquel (2019). La digitalización de la economía y el fin del turismo. En Álvarez Sousa, Antonio, Mantecón, Alejandro y Puertas-Cañaveral, Inmaculada (Eds.). Sociología del Turismo (299321). Madrid: CIS.

Huete, Raquel y Mantecón, Alejandro (2018). El auge de la turismofobia ¿hipótesis de investigación o ruido ideológico? PASOS Revista de Turismo y Patrimonio Cultural, 16(1), 9-19.

Kim, Wonyoung, Jun, Hho M., Walker, Matthew y Drane, Dan (2015). Evaluating the perceived social impacts of hosting large-scale sport tourism events: SCALE development and validation. Tourism Management, 48, 21-32.

Koens, Ko, Postma, Albert y Papp, Bernadett (2018). Is overtourism overused? Understanding the impact of tourism in a city context. Sustainability, 10(12), 4384 .

Lin, Zhibin, Chen, Ye y Filieri, Raffaele (2017). Resident-tourist value co-creation: The role of residents' perceived tourism impacts and life satisfaction. Tourism Management, 61, 436-442.

López-González, José L. (2018a). Ethics and Tourism: In dialogue with Dean MacCannell. Recerca. Revista de pensament i anàlisi, 23, $239-248$.

López-González, José L. (2018b). Exploring discourse ethics for tourism transformation. Turizam: međunarodni znanstveno-stručni časopis, 66(3), 269-281.

Lorenzo Cadarso, Pedro L. (2001). Principales teorías sobre el conflicto social. Norba. Revista de historia, 15, 237-253.

MacCannell, Dean (2011). The Ethics of Sightseeing. Berkeley, CA: University of California Press.

Macedo, Gisela (2020). Las Kellys avisan del fraude de los sellos 'CovidFree' en los hoteles: «Estamos trabajando como antes de la pandemia». 2ominutos. Recuperado de: 
https://www.20minutos.es/noticia/4310618/o/las-kellys-avisanfraude-sellos-covid-free-hoteles/ [Consultado el 15 de julio de 2020].

Marin, Lisa y Halpern, Diane (2011). Pedagogy for developing critical thinking in adolescents: Explicit instruction produces greatest gains. Thinking Skills and Creativity, 6(1), 1-13.

Martín Martín, José M., Guaita Martínez, José M. y Salinas Fernández, José A. (2018). An analysis of the factors behind the citizen's attitude of rejection towards tourism in a context of overtourism and economic dependence on this activity. Sustainability, 10(8), 2851.

Meimand, Sajad. E., Khalifah, Zainab, Zavadskas, Edmundas K., Mardani, Abbas, Najafipour, Amir A. y Ahmad, Ungky N. U. (2017). Sustainability, $9(7)$.

Milano, Claudio, Novelli, Marina y Cheer, Joseph M. (2019). Overtourism and Tourismphobia: A Journey Through Four Decades of Tourism Development, Planning and Local Concerns. Tourism Planning and Development, 16(4), 353-357.

Miramontes, Octavio (200o). Los sistemas complejos como instrumentos de conocimiento y transformación del mundo. En Ramírez, Santiago (Coord). Perspectivas en las teorías de sistemas (83-92). Madrid: Siglo XXI.

Miser, Martina (20 de julio de 2020). «Venís a traernos el virus», la frase que desató una pelea de madrugada en Vilagarcía con un grupo de madrileños. La Voz de Galicia. Recuperado de: https://www.lavozdegalicia.es/noticia/arousa/vilagarcia-dearousa/2020/o7/19/venis-traernos-virus-frase-desato-peleamadrugada-vilagarcia/ooo31595175752169931440.htm [Consultado el 20 de julio de 2020].

Muler González, Vanessa; Coromina, Lluis y Galí, Nuria (2018). Overtourism: residents' perceptions of tourism impact as an indicator of resident social carrying capacity - case study of a Spanish heritage town. Tourism Review, 73(3), 277-296. 
Musinguzi, Dan (2019). A review of the application of social exchange theory in tourism research. En Gursoy, Dogan y Nunkoo, Robin (Eds.). The Routledge Handbook of Tourism Impacts: Theoretical and Applied Perspectives (498-506). New York: Routledge.

Oklevik, Ove, Gössling, Stefan, Hall, C. Michael, Steen Jacobsen, Jens K., Grøtte, Ivar P. y McCabe, Scott (2019). Overtourism, optimization, and destination performance indicators: a case study of activities in Fjord Norway. Journal of Sustainable Tourism, $27(12), 1804-1824$.

Pizam, Abraham (1978). Tourism's Impacts: The Social Costs to the Destination Community as Perceived by its Residents. Journal of Travel Research, 16(4), 8-12.

Royo Vela, Marcelo y Ruiz Molina, María E. (2009). Actitud del residente hacia el turismo y el visitante: factores determinantes en el turismo y excursionismo rural-cultural. Cuadernos de turismo, $23,217-236$.

Russo, Antonio P. y Scarnato, Aessandro (2018). Barcelona in common: A new urban regime for the 21st-century tourist city? Journal of Urban Affairs, 40(4), 455-474.

Stylidis, Dimitrios, Biran, Avital, Sit, Jason y Szivas, Edith M. (2014). Residents' support for tourism development: The role of residents' place image and perceived tourism impacts. Tourism Management, 45, 260-274.

Um, Seoho y Crompton, John L. (1987). Measuring resident's attachment levels in a host community. Journal of Travel Research, 26(1), 27-29.

Uriely, Natan y Belhassen, Yaniv (2006). Drugs and risk-taking in tourism. Annals of Tourism Research, 33(2), 339-359.

Wang, Sousheng y Chen, Joseph S. (2015). The influence of place identity on perceived tourism impacts. Annals of Tourism Research, $5^{2}, 16-28$.

Wen, Jun, Meng, Fang, Ying, Tianyu, Qi, Hongxia y Lockyer, Tim. (2018). Drug tourism motivation of Chinese outbound tourists: 
Scale development and validation. Tourism Management, 64, $233-244$.

Artículos de prensa analizados

Castedo, Antía (26 de agosto de 2014). El hartazgo de Barcelona con el turismo de borrachera. BBC Mundo. Recuperado de: https:/www.bbc.com/mundo/noticias/2014/o8/140825_turismo_bor rachera_barcelona_ac [Consultado el 2 de septiembre de 2019].

Congostrina, Alfonso L. (12 de agosto de 2017). Los vecinos de la Barceloneta toman la playa en contra de los excesos del turismo. El País. Recuperado

de: https://elpais.com/ccaa/2017/o8/12/catalunya/1502533459_674138.ht $\mathrm{ml}$ [Consultado el 2 de septiembre de 2019].

Donel, Maritxel (1o de junio de 2017). ¿Realmente hay turismofobia en Barcelona? Los barceloneses están mayoritariamente a favor del turismo pero reclaman una mejor gestión ante la masificación. $L a$ Vanguardia. Recuperado de https://www.lavanguardia.com/local/barcelona/20170610/423263910 854/turismofobia-barcelona-masificacion-turismo-guell-sagradafamilia.html [Consultado el 2 de septiembre de 2019].

El turismo centra gran parte de las quejas de los ciudadanos de Barcelona $(15$ de febrero de 2017). Hosteltur. Recuperado de: https://www.hosteltur.com/120505_turismo-centra-gran-partequejas-ciudadanos-barcelona.html [Consultado el 2 de septiembre de 2019].

Fanjul, Sergio C. (21 de abril de 2016). 'Turismo de Borrachera': la ruta al desenfreno etílico que esconde España. El País. Recuperado de: https:/elpais.com/elpais/2016/o4/2o/tentaciones/1461172147-507687. html [Consultado el 2 de septiembre de 2019].

López, Helena (12 de agosto de 2017). Cadena humana en la Barceloneta contra el modelo turístico. El Periódico. Recuperado de: https://www.elperiodico.com/es/barcelona/20170812/protesta- 
barceloneta-modelo-turistico-cadena-humana-6220599 [Consultado el 2 de septiembre de 2019].

Márquez, Carlos (15 de septiembre 2018). Manifestación vecinal en Barcelona: Ya no es el turismo; ahora es el miedo. El Periódico. Recuperado

de:

https:/www.elperiodico.com/es/barcelona/20180915/manifestacionvecinal-barcelona-contra-inseguridad-incivismo-703640o [Consultado el 2 de septiembre de 2019].

Más de mil vecinos «ocupan» la Rambla de Barcelona en contra del «turismo masificado» (28 de enero de 2017). La Vanguardia. Recuperado de:

https://www.lavanguardia.com/local/barcelona/20170128/4137941875 55/manifestacion-vecinos-rambla-barcelona-turismo.html [Consultado el 2 de septiembre de 2019].

Pauné, Meritel M. y Paola, Martí (12 de agosto de 2017). La Barceloneta protesta en la playa contra la turistificación y la pérdida de vecinos. La Vanguardia. Recuperado de: https://www.lavanguardia.com/local/barcelona/20170812/434785973 84/protesta-barceloneta-playa-turismo-alquileres.html [Consultado el 2 de septiembre de 2019].

Un millar de personas protestan contra el turismo de borrachera en Barcelona (zo de agosto de 2014). El Mundo. Recuperado de: https://www.elmundo.es/cataluna/2014/o8/30/5402054aca4741841b8 b4576.html [Consultado el 2 de septiembre de 2019].

Vecinos de la Barceloneta toman la playa contra el turismo «incívico» (12 de agosto de 2017). Diario Sur. Recuperado de: https://www.diariosur.es/nacional/sucesos/vecinos-barcelonetatoman-20170812153015ntrc.html?ref=https\%3A\%2F\%2Fwww.google.es\%2Furl\%3Fsa\%3Dt [Consultado el 2 de septiembre de 2019]. 